\title{
COOPERATION AS A DRIVING FORCE IN NORDIC IT
}

\author{
Jussi Tuori \\ President of the Finnish Computer Society 1970-1972, DP Director of Kansallis-Osake- \\ Pankki1973-1980; jussi.tuori@pp.inet.fi
}

\begin{abstract}
The paper describes the early user cooperation and states that it was an essential prerequisite of high level of IT in Nordic countries. It describes the cooperation in the domestic, Nordic and international level. It gives many examples but is not comprehensive by any means. It gives a very pessimistic view of the future.
\end{abstract}

Key words: Cooperation between users, users and research, users and manufacturers, domestic level, Nordic level, international level

\section{INTRODUCTION}

Even in the call for contributions to this conference, cooperation is mentioned as one of the essential factors for the success of Nordic IT. I am prepared to go even further, I believe that the Nordic countries never would have reached the high level of IT they now have, had it not been for the good user cooperation in the early days. We can be proud of always having been very advanced, compared to other countries, in using the latest technology and the most effective working methods, as well as in creating applications tailored to help users in their internal and external operations.

My point of view is a user point of view. In this paper, I wish to describe how the cooperation between different users, between users and suppliers, and between users and research institutions was organized. I will also try to analyze some of the results of this cooperation. I will not describe the scientific or technical cooperation. In that area, sharing the results and 
experiences has always been - and still is - a normal and natural practice. In the business world this is not the case.

Despite the fact that the practice of sharing results and experiences is not very usual in the business world, we were, for several reasons, able to achieve remarkable results with cooperation in the early years of IT we were. In business, IT was not considered as a competitive factor, and in fact, the top management of most companies was not particularly concerned with it. In most cases, it was a tool for rationalization; it could improve the profitability, but it did not have any direct impact on business itself before sometime in the middle of the nineteen seventies. It was not until then that many realized what an effective tool IT is for building up the competitive edges. From that time on, we really started to use IT to improve business processes and moved from internal to external processes.

It is also true to say that it was only in the late seventies that we could give top and middle management some tools they could actually use. We can all remember how we tried to sell what our top management knew as MIS systems. The truth was that those systems were nothing else than enormous accounting systems, which could only help our top management very slightly. We who were in IT actually knew very little about the working processes and needs for information within the management.

In all the Nordic countries, the business environment was local and quite closed. The big waves of internationalisation were still ahead. The countries are small, and one can say that everybody knew everybody. The people working in IT were young and inexperienced, and so it was natural for them to try to find colleagues and cooperation partners.

\section{DOMESTIC COOPERATION}

I shall start with the local and domestic cooperation within the countries. My natural example is Finland, which is the country I know best. The representatives of other Nordic countries might feel somehow offended by the fact that I am not going to recapitulate the development in their countries as well. However, our countries have been so similar that such a full recapitulation would result in very much repetition, and unfortunately, there is not enough time for that in this context.

A main forum for cooperation was the Finnish Computer Society, founded in 1953 as a society for punched card professionals. They changed the name in 1961 and it became the Computer Society. It was quite exceptional that companies joined the society as company members and even paid the membership fees for their employees right from the beginning. Thus, the cooperation was approved and even favoured by the companies. 
All the people active in IT management, systems and operations, etc., attended the meetings of the society. The society was a little like a club. A typical feature was the joint dinners after the meetings. Even a newcomer could meet all the pioneers and the top managers of IT during those meetings. The discussions were open and vivid. This is not possible anymore.

The need for cooperation was very big in the beginning of the sixties. As it was a totally new technology that was being introduced, everything had to be created from scratch. In fact, only the elementary computers and programming languages existed. There were no methods and practices in system work. We can all remember how we were drawing elementary flowcharts with those small green drawing sheets. There were no practices for organizing the IT- or DP-work or the project management. Finally yet importantly, there were neither experienced people nor any kind of training available. The suppliers were offering courses in programming, but that was all. The only way to solve these problems was cooperation.

The State Computer Centre led the development of the system work processes and created a model for system work in close cooperation with other users. The big users solved the training together. The first two courses were organised by the Research Foundation for Applied Mathematics and Data Processing residing in Turku and chaired by prof. K.V. Laurikainen. Already at that time the IT managers of the big users took the actual responsibility for the courses. The driving force was Eero Kostamo. Another foundation to continue the activities was under planning. However, it could not be realised. The Computer Society did not have resources enough for training activities at that time, so the IT managers founded a training company, Tietojenkäsittelyneuvonta Oy in 1963. The system work model developed at the State Computer Centre was the basis of the training courses. The training material was written jointly by the EDP-managers of the biggest users, and all the case studies came from these same big users. These system courses were the basis of the training of system professionals until the late seventies.

Training was one of the most important subjects discussed by the users also later on. The Society and the people active in the Society had a decisive role in founding the ADP Institute in 1970. An association was formed to support the new institute financially, and to give the training a strong user point of view. That institute was the basic training centre for new system professionals and programmers in Finland all through the following twenty years. Now the institute is part of the Finnish standard educational system.

However, we must not forget the invaluable role played by the universities and colleges in the training activities within IT. They rapidly and effectively expanded their activities from the beginning of the seventies. 
In 1971, the Computer Society transformed into a federation with independent local and even countrywide problem-oriented associations as its members. The new structure made it possible for the Federation to expand both its membership and its activities significantly, and so it happened. Now the Federation has 27 member associations, which have about 800 company members and about 23,000 personal members.

Training and education - not the basic, but complementary training - was one of the main activities of the Federation throughout the years. For instance, the Federation organized large annual conferences, and still does. The Federation has also had an important role in creating teaching chairs in IT at several universities. Other important activities include publication of books and journals, as well as research and other kinds of development, among which are standards and IT terminology (which is still under development). Last, but not least, the Federation has played a part in working with government, authorities, legislation, media, etc., in order to improve the basis for developing IT. As for international activities, I shall return to them later on.

The founding of the Development Centre for Information Technology (TIEKE) in 1981 is one major project of national importance. The need for more resources in the research about and the development of IT outside the universities was enormous. Many people felt that the scientific work at the universities was so theoretical that the users needed more practical research work. The Finnish State, the Federation, and the ADP Institute founded the Development Centre. It took over all the research and standardisation projects that the Federation had had. Very soon, it played a very active role in data transmission projects. The Centre has been very successful. It has now changed its name and is called the Finnish Information Society Development Centre.

Already in the seventies, telecommunication was a very good example of user cooperation. It was at the same stage of development as the system work had been a decade earlier. There was no standard and procedures required agreement. The only thing that was certain was that there existed an enormous need for telecommunication. The international EDI-work could not give solutions for the specific Finnish problems. Therefore, a joint organisation for operators and users was founded in 1981, in order to create standards and procedures for data transmission between organisations (OVT). The first structure was ready in 1986. (The history after that would need at least a half-day session to be properly rendered.)

The banks had their own project for the data transmission between themselves and that between banks and their customers (POLM). This was a big and successful project. It started as early as 1969 , and it developed in different stages up to eighties. It was organised within the Finnish Bankers Association. We can proudly say that the result has been one of the most 
advanced and efficient payment systems in the world. One explanation for that is that we only had seven banks or banking groups with their own computer centres and systems. The situation is much worse in bigger countries with thousands of banks. The other Nordic countries had similar projects, for instance SIBOL in Sweden.

The users were equally active to create a new operator for data transmission. They were not happy with the possible monopoly of the PTT, so they founded a new company, Datatie ("Dataway"), together with the private local operators. We can say that this was an important starting point in opening the competition within data communication in Finland. These are only a few examples of the user cooperation.

The computer manufacturers already created their user groups in the sixties. Some of those have been extremely successful. Many of them operated both domestically and internationally. The one that was best-known in Finland was Compus, the association for Nokia users, such as Siemens, GE, Honeywell, and Bull. Especially during the 1970s, its activities were versatile and wide, starting from conferences that had a few hundred delegates, included domestic and international excursions, comprised tens of simultaneous working groups, and published the reports of the groups as a book.

Additionally, the big IBM users founded an unofficial association to defend their interests against IBM already in the sixties. In those days, we really needed that kind of user interest watchdog. Even if the task of this association was mainly to defend the interests of users against the computer manufacturer, it also spun off several joint projects to improve both the system work and the effective operations with IBM computers.

The situation with specific user organisations according to computer manufacturer was, naturally, often problematic. The manufacturers used the organisations as marketing tools, and the users tried to defend their interests against the manufacturer. It was very difficult to achieve some balance between the two parties.

There have also been several groups within or outside the Computer Society or associations with joint interests for instance in programming techniques, privacy, auditing, social matters, etc.

I want to end the domestic part by mentioning the club for IT-directors of large users and university professors. The goal was to update the knowledge in the latest developments in a very confidential atmosphere, no protocols, no papers, only high-level presentations and afterwards some social programme, for instance sauna. The membership has been limited to 25 , and new members can join only by invitation. The club was founded in 1978 and is still going strong.

Just as a curiosity, some years ago some people within the Computer Society at last realized that IT is already a mature field with people of 
mature age. They started a club for retired people called "the Grey Panthers". Using the idea from the "Senior Club" organised in Denmark by Erik Bruhn, the model was modified for the Finnish context and is now running with success.

\section{NORDIC COOPERATION}

I will start the Nordic level with the cooperation within different industries. In the sixties and seventies, Nordic companies were mainly domestic companies. They might have had some alliances with companies from other Nordic countries. Actually, there were no truly global or even international company. In most cases, there was not so much competition between countries. Often, we preferred cooperation instead of competition. The cooperation was either bilateral or multilateral.

This was true for instance in my industry, banking. The commercial banks were grouped in two chains, the Nordic group and the Scandinavian group. It was, however, very natural to exchange IT experiences within the whole industry. The commercial banks in the Nordic countries had started their biannual organisational conferences already in 1948. They were twoday conferences with state-of-the-art presentations and many working groups. From the seventies onwards, the main emphasis was on IT. The competition between banks and the bank crisis ended this cooperation. The last conference was held in 1988 on Bornholm.

Apart from the professional programme, the conferences offered the possibility to create even life-long friendships in very pleasant surroundings. Here I must stress that one of the most important prerequisites for a successful cooperation is a good and working personal relationship. The conferences also led to interesting joint projects. The eighties and internationalisation changed everything. Those conferences died in the mideighties, the friendships, however, are still going strong. Similar type of cooperation was created also in many other industries, but I'm not going to mention them simply because I don't know them that well.

The multilateral Nordic cooperation has been very active. At the end of the fifties and the beginning of the sixties, there were many mainly bilateral contacts between Nordic countries. In most cases, they were of a technical or scientific nature. Building the first computers, for instance, aroused many active contacts. From 1959 on, there had been NordSAM conferences. They were very technical and scientific, discussing the different features of the early computers and the theory behind them.

However, there was an enormous need for an organised cooperation also in economic life and between users there. On 23 May 1966, the Nordic Data 
Union (NDU) was established in Helsinki by the Nordic Computer Societies, and an important part of the joint activities was channelled through it.

The NordSAM conferences transformed into the annual NordDATA conferences. Their nature changed and they became user dominated. The main part of the papers was state-of-the-art-type papers. I personally think that it was very important to keep the active interaction between users and scientists alive. All that resulted in a huge success. At the largest NordDATAs there were between two and three thousand participants. The conferences circulated between the four Nordic countries (Iceland was not included as organiser). NordDATA also became the Nordic computer societies' main source of income. However, this product died step by step in the early nineties.

The Norwegian-Danish joint journal Moderne Databehandling is an example of early bilateral cooperation. The Norwegians had published the journal for ten years in 1966 when the Danes joined in. The journal was published until 1971, when the Nordic journal was established.

The other big project was a joint professional journal DATA which was created in 1971. Erik Bruhn will describe the birth, life, and death of DATA more closely in his paper. However, in spite of the success at the start, the journal did not have resources to compete with the big commercial journals, and the last issue appeared in December 1988. There still is a scientific Nordic journal, BIT. It is a highly valued journal and the resources needed are much smaller than in commercial journals. Through an initiative taken within the BIT cooperation, two other scientific journals in the Nordic countries have also been founded.

The third significant line of activities was the NDU seminars. The main purpose of these seminars was to gather IT people, politicians, top management from business and scientists together to discuss social, economic, educational, etc., problems related to the introduction of this new technology. These seminars were well attended, each having between fifty and a hundred delegates. Altogether ten seminars were organised in the years 1975-1985. Among the topics discussed were "personal data and integrity", "the vulnerability of the society", "he need for an IT policy in the society", "IT and educational policies". We can say that some of the seminars had a quite far-reaching impact in the Nordic countries. Especially the topics on integrity and education set off a lively discussion in some countries, which then led even to new legislation.

One cannot overemphasize the role of Erik Bruhn when talking about the Nordic cooperation. He was Mr. NDU since the late sixties. He made the journal DATA on his own. The NDU seminars were his idea, and they were totally managed by him. He deserves our warmest applause.

As the last example of Nordic cooperation, I want to mention the joint excursions, which the Swedes initiated. The target country was USA, and 
the excursions could last for as long as three weeks and would have about sixty participants forming different groups, each with their own programme, according to their line of business. The excursions were organised during ten years, starting in mid-sixties. They considerably helped the users to have a state-of-the-art knowledge - about what was happening on the biggest world market - and to see what new ideas we could bring home, if any. In this connection, one must mention another pioneer, and that is Kjell Hultman, who, on top of his other domestic and international activities, organised these excursions.

\section{INTERNATIONAL COOPERATION}

Some words will also have to be said about the international cooperation. The main channel was the International Federation for Information Processing (IFIP), founded as early as 1959 in Paris. The Nordic contribution to IFIP has been remarkable both in the organisation and within its technical committees and working groups. The Scandi-mafia has always held high positions, from the IFIP Presidency to the TC Chairmanships. They have been fulfilling their duties in an outstanding way. We Nordic people can be proud of being reliable; we do what we have promised to do. Also technically and professionally, we have always been advanced.

IFIP has grown into a large organisation over the years. It has always organised a great number of congresses, conferences, symposia, seminars and working meetings. IFIP is not developing new programming languages anymore, like Algol in the early sixties, but is dealing with a great variety of important topics on everything from a highly technical to a social and cultural nature. IFIP has organised large world congresses, at first every three years, and then every two years. Their development closely resembles the history of the NordDATA conferences. In the sixties, seventies and early eighties they had thousands of delegates, even more than four thousand. The number of delegates has since been decreasing, and is now around a thousand. The IFIP world congress was held in Stockholm in 1974. That was a big success but required a huge effort from the hosts. A special feature during that congress was that a newsletter was given out every day. This was the responsibility of our Nordic journal DATA.

The time span treated by this conference is up to the year 1985. Yet, it must be mentioned that new platforms for cooperation have turned up. An important one is the Council of European Professional Informatics Societies (CEPIS). One very interesting topic there has been the PC driving licence. This is a Finnish innovation, and it has been highly successful in many countries. 
I have previously described the Nordic cooperation between banks, so I must mention also the international cooperation to develop the payment systems, SWIFT. It started already in 1979, and the Nordic banks were very active there. There have also been similar projects in many other industries, such as aviation, travel agencies, etc.

The importance in the Nordic countries of the EU as a platform for cooperation within IT has increased considerably since Sweden and Finland joined the EU. One can say that the European platform is already the main platform instead of the Nordic.

The nature of IT is so international, that it is impossible even to try to describe comprehensively the international cooperation of the Nordic countries on various levels in a paper like this one. However, I happen to have personally been actively involved in a very specific cooperation, which might be mentioned here, perhaps as a curiosity. For fifteen years, I was the Finnish chairperson of the working group in Cybernetics of the ScientificTechnical Cooperation Committee between Finland and the Soviet Union. The Committee was a State Committee, so it had a strong political backing. The first agreement in Cybernetics was signed in my sauna in 1970 between the Finnish Computer Society and the Soviet Academy of Sciences. The cooperation was surprisingly active. We had annual symposia. We exchanged delegates for longer periods - sometimes as long as nine months; the total annual number of exchange days was around four hundred. We had joint development projects mainly of scientific nature. However, something collapsed and so did these activities.

\section{CONCLUSION}

What, then, will the future be like? Unfortunately, from the cooperation point of view it does not look very good. The economical environment has changed totally. Even the Nordic companies are in many cases multinational. IT is now one of the most important competitive factors for the companies. One can also say that IT is already everywhere in our society, in the companies, in working life, and in our homes. The World Wide Web has changed the world. The old centralised IT organisations in the companies are gone. The IT people cannot form a club anymore. There are so many people and players that the old familiar feeling is missing. The good old days are gone forever. 